\title{
Hydrogen-absorbing alloy-based metal-hydride actuation for application in rehabilitative systems
}

\author{
Kyong Kim ${ }^{\mathrm{a}}$, Seong Hyun $\mathrm{Kim}^{\mathrm{a}}$, Sung Hoon $\mathrm{Kim}^{\mathrm{b}}$ and Chang Ho $\mathrm{Yu}^{\mathrm{c}, *}$ \\ ${ }^{a}$ Department of Medical and Electronic Device, Chungbuk Provincial College, Chungbuk 29046, Korea \\ ${ }^{\mathrm{b}}$ Department of Electronics Convergence Engineering, Wonkwang University, Jeonbuk 54538, Korea \\ ${ }^{\mathrm{c}}$ Division of Convergence Technology Engineering, Chonbuk National University, Jeonbuk 54896, \\ Korea
}

\begin{abstract}
.
BACKGROUND: A lightweight rehabilitation assisting system is required to help the aged and disabled with daily life activities, thereby improving the quality of their lives.

OBJECTIVE: This paper discusses the development of a metal-hydride (MH) actuator, with excellent heat transfer performance, for application in a rehabilitative system incorporating an $\mathrm{MH}$ module.

METHODS: The operating mechanism of MH actuators requires that the mechanical power of the pneumatic actuator only be generated via heat transfer through a Peltier element and the absorption/desorption of a hydrogen-contained MH module. To achieve this aim, a 3D model was first designed for two MH modules, and a thermal analysis was carried out according to the type of contact with the Peltier elements to fabricate an MH module with improved heat transfer performance. LabVIEW (National Instruments) was used for automatic temperature control of the Peltier element in the $\mathrm{MH}$ actuator driving experiment. $\mathrm{Zr}_{0.9} \mathrm{TI}_{0.1} \mathrm{Cr}_{0.6} \mathrm{Fe}_{1.4}$, which yields a pressure-composition-temperature (PCT) curve of appropriate pressure and temperature ranges for a rehabilitative system, was selected as the hydrogen-absorbing alloy.

RESULTS: In addition, the temperature conditions of the MH actuator driving experiment were restricted by two temperature control ranges $\left(30-40^{\circ} \mathrm{C} / 30-50^{\circ} \mathrm{C}\right)$ of the Peltier element. Within these Peltier element temperature ranges of $30-40^{\circ} \mathrm{C}$ and $30-50^{\circ} \mathrm{C}$, results showed that the $\mathrm{MH}$ actuator was driven in the ranges of 2-3 atm and 2.5-3.5 atm, respectively.

CONCLUSIONS: These findings indicate that the MH actuator proposed in this paper can be utilized to drive a rehabilitative system for elbow and knee joint exoskeletons.
\end{abstract}

Keywords: Metal-hydride actuation, MH module, rehabilitation device

\section{Introduction}

As the populations of the aged and disabled increase, various types of rehabilitative systems have been developed for them. Such systems are termed rehabilitation training systems, which are therapy and/or assistive systems designed to support activities of daily life. Patients are typically required to travel to a university or rehabilitation hospital to use the motor rehabilitation-purposed systems. Because

\footnotetext{
${ }^{*}$ Corresponding author: Chang Ho Yu, Division of Convergence Technology Engineering, Chonbuk National University, Jeonju, Jeonbuk 54896, Korea. Tel.: +82 63472 2898; Fax: +82 63270 4226; E-mail: combo418@ nate.com.
}

0928-7329/18/\$35.00 (C) 2018 - IOS Press and the authors. All rights reserved

This article is published online with Open Access and distributed under the terms of the Creative Commons Attribution NonCommercial License (CC BY-NC 4.0). 
therapy is the primary goal, most rehabilitative systems are large and occupy a considerable amount of space. Conversely, an aid system assists activities of daily life (ADL), such as walking, of the aged or chronically disabled both in and out of their homes. This system is composed of an exoskeleton, which is attached to the side of the target upper or lower extremity body part, a curved component, which fixes the exoskeleton to the body of the user, and an actuator to drive movement.

To enhance the comfort of a daily life assistive system, the system needs to be small and light, particularly to ensure high transportability. Existing assistive systems have employed a driving source that drives the motions of each joint by means of pneumatic and hydraulic devices. However, because pneumatic and hydraulic devices require a separate pneumatic generator, or are heavy, implementation in assistive systems is not preferred. Recently, because high-power micro motors have been increasingly developed, most rehabilitative systems have come to incorporate a motor. Unfortunately, electric motors, which generate joint torques sufficient to support the ADL of patients wearing the system on their upper or lower extremities, remain to be heavy for users. In the case of myPro (Mymyo Inc.), which assists flexion-extension elbow motions of the aged, the driving electric motor constitutes $40 \%$ of the weight of the entire system. Furthermore, new types of driving units, such as shape memory alloy actuators and series elastic actuators (SEAs), cannot generate sufficient torques to assist motions of upper and lower extremities.

Many researchers have focused on developing medical and rehabilitation equipment using hydrogenabsorbing alloys. As an example, Shimizu et al. used a metal-hydride actuator to determine the forces of elbow joint motions [1,2]. Wakisaka et al. applied the driving principle of metal-hydride actuators to implement them in various types of medical and rehabilitation equipment $[3,4]$. Ino et al. performed a study on a bellow-type soft metal-hydride actuator for use in rehabilitation and aid equipment for those suffering from dyskinesia due to stroke or old age [5-7]. Kurosaki et al. developed a simple metal-hydride actuator that included a hydrogen-absorbing alloy with a copper plate [8]. Sato et al. utilized the principle of a metal-hydride actuator to develop a mobility assistive system that is able to help a patient stand up from a wheelchair [9]. Ino et al. fabricated a tiptoe passive motion device by implementing a flexible metal-hydride actuator to prevent bedsores [10,11]. Lloyd and Kim employed hydrogen-absorbing alloy technology and a pneumatic actuator to test a new metal-hydride actuator [12]. Kwon et al. carried out a study to develop a new metal-hydride actuator with a hydrogen-absorbing alloy that joined eight copper pipes via welding [13,14]. Additionally, Kim et al. designed a new metal-hydride actuator that used copper to improve heat transfer efficiency $[15,16]$.

Metal-hydride (MH) actuators are being developed to reduce the weight of the driving component in assistive systems that are designed to support activities of daily life. Hydrogen gas contained in MH follows the process of hydrogen absorption-desorption according to the thermal change (heating-cooling) applied to the MH. An MH actuator, which is able to interchangeably use thermal energy and mechanical energy, can store as much as 1,000 times the volume of the alloy; additionally, it has the advantages of being small while also generating high power. However, one absorption-desorption cycle of hydrogen in the existing $\mathrm{MH}$ actuator is time expensive, causing it to be a disadvantageous application in a system designed to assist upper and lower extremity joint motions for ADL. Regarding the performance of $\mathrm{MH}$ actuators, the heat transfer efficiencies of an $\mathrm{MH}$ module and heat source of a peltier device are the primary causes of hydrogen absorption-desorption increase. Thus, fundamental research on the design of the heat source and heat transfer of an $\mathrm{MH}$ module is needed to enhance the performance of $\mathrm{MH}$ actuators.

In this study, a MH module able to improve heat transfer performance was fabricated, and a $\mathrm{MH}$ actuator, which was driven according to a predetermined temperature range of a Peltier element, was developed. The hydrogen-absorbing alloy was selected based on the driving constraints of the rehabilitative 


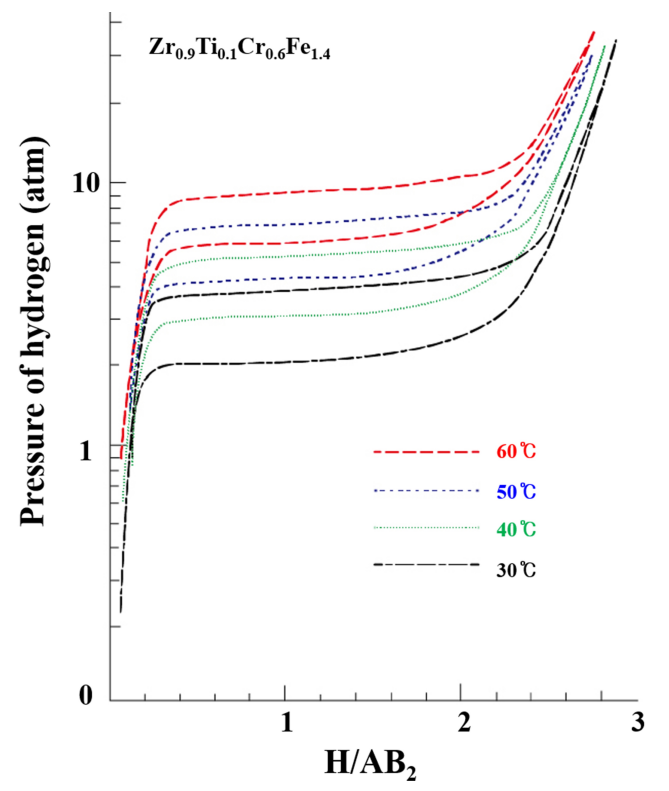

Fig. 1. PCT curve of selected hydrogen-absorbing alloy.

system for upper and lower extremity exoskeletons; in addition, the $\mathrm{MH}$ actuator driving experiment was performed according to the constraints of the temperature range.

\section{MH selection and MH module design}

\subsection{Selection of hydrogen-absorbing alloy}

Because hydrogen-absorbing alloys possess a significantly higher hydrogen storage capacity per unit volume than liquid or gaseous hydrogen, a micro $\mathrm{MH}$ actuator, which is driven by a small amount of hydrogen-absorbing alloy, can be developed. Furthermore, the hydrogen absorption and desorption of hydrogen-absorbing alloys can be controlled by implementing a PCT curve with varying pressure and temperature. As a result, the hydrogen-absorbing alloys can be used as a rehabilitative system power source. To drive a rehabilitation system exoskeleton designed to assist joint movements of upper and lower extremities such as elbow and knee joints, a safe four-component hydrogen-absorbing alloy was selected for used in this study because it satisfies the low temperature (temperature range: $30-60^{\circ} \mathrm{C}$ ) and low pressure (10 atm or below) requirements; moreover, it possesses a relatively reduced hysteresis curve, and also yields an adequate plateau pressure. Figure 1 illustrates the PCT curve of $\mathrm{Zr}_{0.9} \mathrm{TI}_{0.1} \mathrm{Cr}_{0.6} \mathrm{Fe}_{1.4}$, and the horizontal axis represent hydrogen storage and the longitudinal axis mean hydrogen pressure, which satisfies the low temperature and low pressure requirements for driving a rehabilitative system. Small HM specimens between 5-20 g were fabricated using $99.99 \%$ high-purity material.

\subsection{Design of metal-hydride module}

The hydrogen-absorbing alloy utilized in the MH module absorbs heat from two Peltier elements contacting both sides of the module. Hydrogen gas is heated and cooled by the heat from the Peltier 


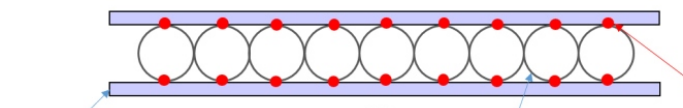

(a)

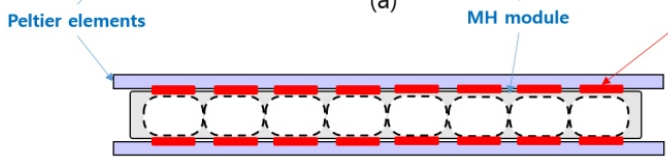

(b)

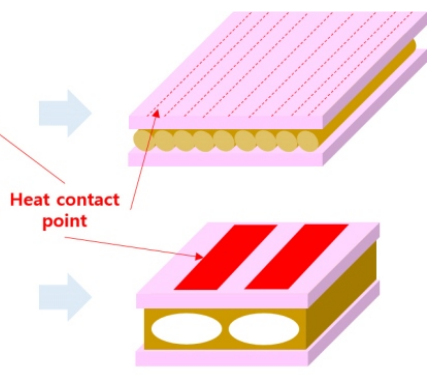

Fig. 2. MH module concept; (a) line contact, and (b) face contact.

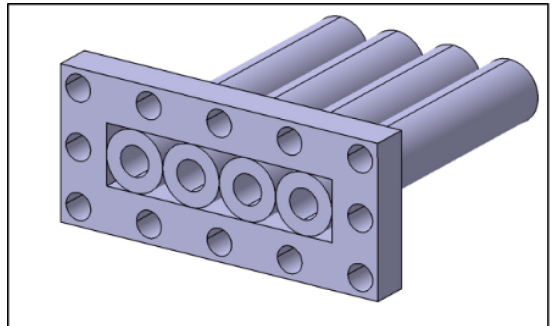

(a) Line contact

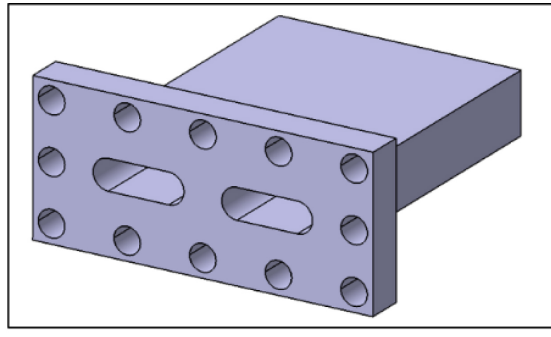

(b) Face contact

Fig. 3. MH module with (a) line contact (Type 1) and (b) face contact (Type 2).

elements, and is stored within the MH module. This hydrogen gas drives a rehabilitative system by generating an absorption-desorption mechanism.

To improve heat transfer performance, a MH module was fabricated to suit a conventional MH actuator by welding nine copper tube cylinders. The MH module and Peltier elements were in line contact, as shown in Fig. 2a above [15]. Considering the MH module of the conventional MH actuator, an improved MH module with enhanced heat transfer performance needs to be designed to sufficiently support a rehabilitative system. This new hydrogen-absorbing alloy-containing MH module alloy should be designed to have face contact with Peltier elements, as shown in Fig. 2b; in addition, the difference in heat transfer efficiency between this new face contact and the conventional line contact needs to be analyzed.

Because the MH module of the conventional $\mathrm{MH}$ actuator comprises eight welded copper cylinders, the module has a line contact with Peltier elements. The MH alloy in the cylinders of each MH module drives the MH actuator as hydrogen is absorbed or desorbed by the heat transfer through the line contact with Peltier elements. As shown in Fig. 3a, a 3D model of the line contact-type MH module was designed to analyze the heat transfer efficiency of the module, which is regulated by the heating and cooling of the Peltier elements. The MH module had dimensions of $40 \mathrm{~mm} \times 40 \mathrm{~mm}$ and was made of copper.

To enhance the driving performance of the $\mathrm{MH}$ actuator, a face contact design was incorporated to increase the contact area with the Peltier elements. Figure $3 \mathrm{~b}$ shows an $\mathrm{MH}$ module designed to have a size identical to that of the conventional line contact-type MH module; it also comprised two holes for the hydrogen-absorbing alloy. This face contact-type MH module was a plate-shaped rectangular parallelepiped with a reduced number of holes and a face with dimensions of $40 \mathrm{~mm} \times 40 \mathrm{~mm}$. The material used was copper. 

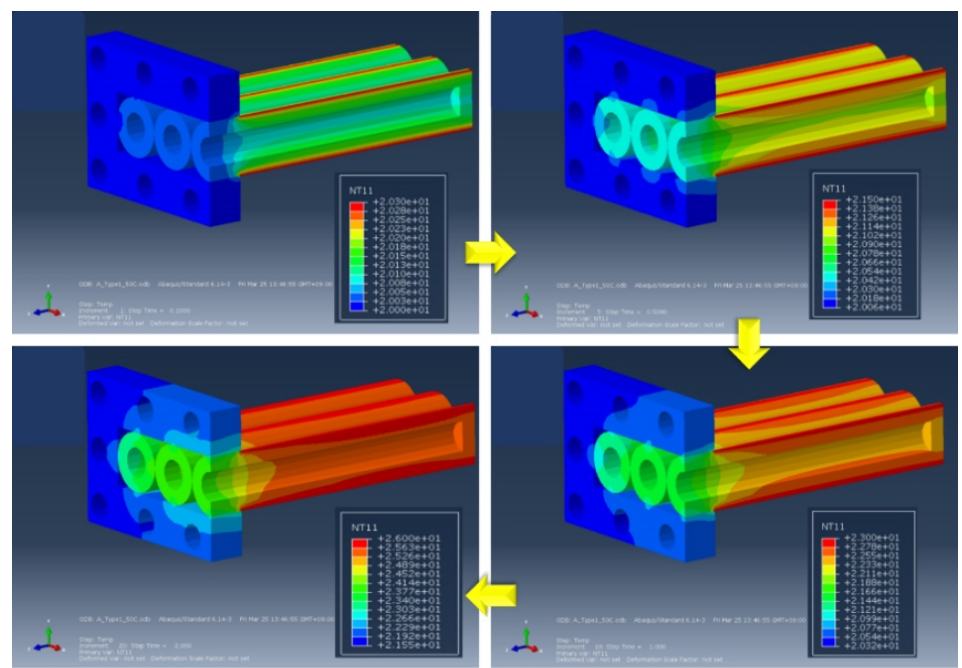

Fig. 4. Temperature change-induced progression of heat transfer in line contact condition.
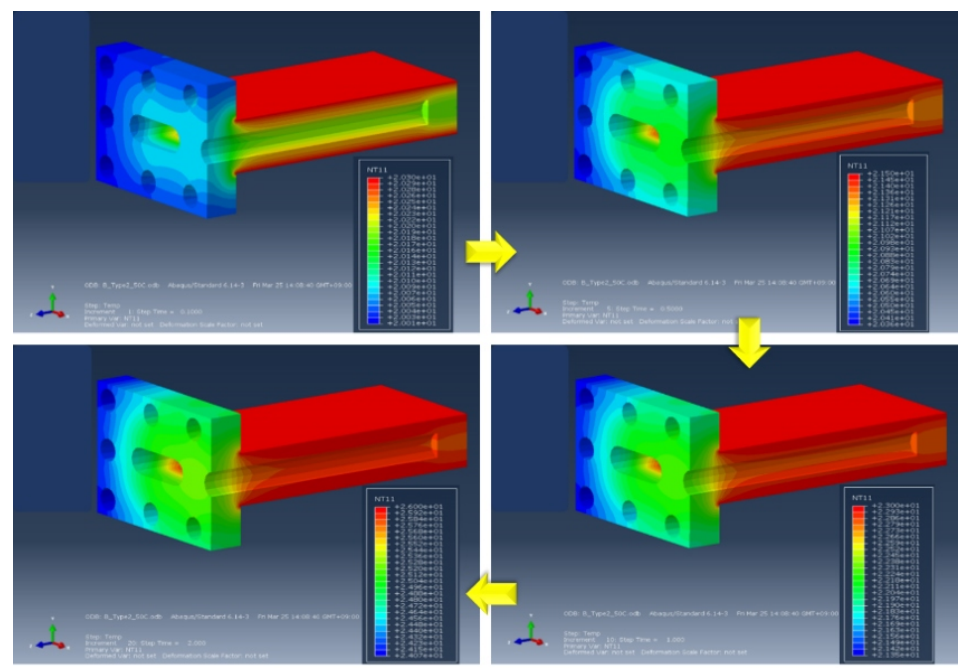

Fig. 5. Temperature change-induced progression of heat transfer in face contact condition.

\subsection{Design of metal-hydride module}

The two types of MH modules were compared in terms of heat transfer efficiency, which was based on the heating and cooling conditions of the Peltier elements, to analyze their respective heat transfer ability. The temperature range for the thermal analysis according to the PCT curve of the selected hydrogen-absorbing alloy was $30-60^{\circ} \mathrm{C}$. In this experiment, the heat transfer ability of the two types of MH modules was tested by simulating different heating and cooling temperature conditions. The heat transfer simulation analysis results were generated via Abaqus software (ABAQUS 6.14-3, Dassault systemes), demonstrating that the face contact-type $\mathrm{MH}$ module exhibited approximately 4.4 times the heat transfer efficiency of the line contact-type MH module. 


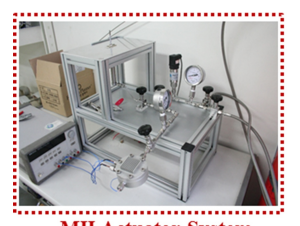

MH Actuator System

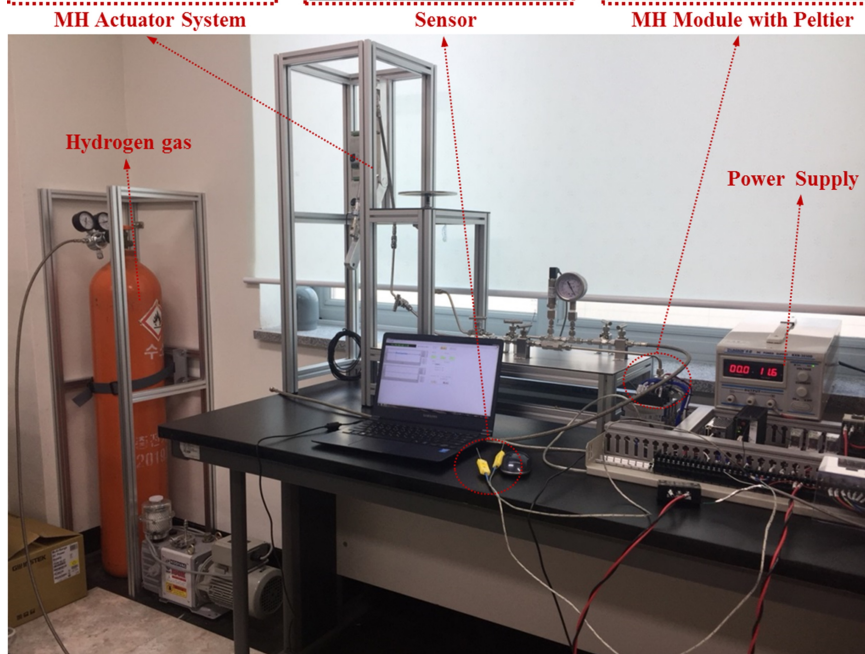

Fig. 6. Experimental setup.

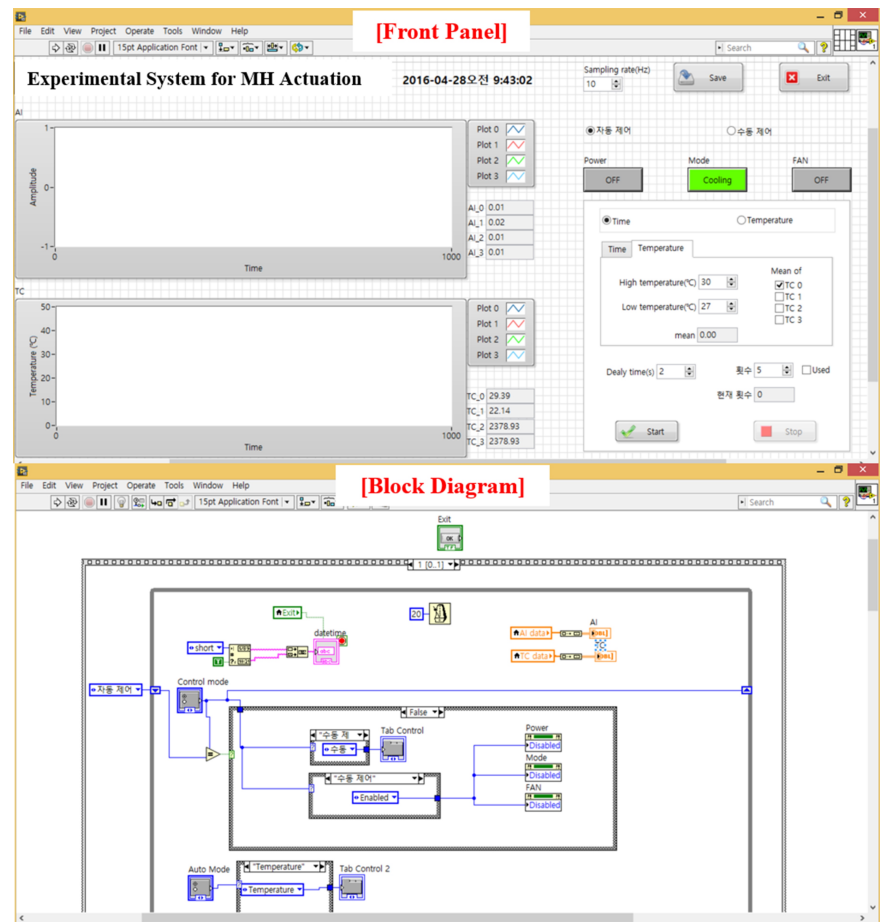

Fig. 7. Software used to drive the $\mathrm{MH}$ actuator. 

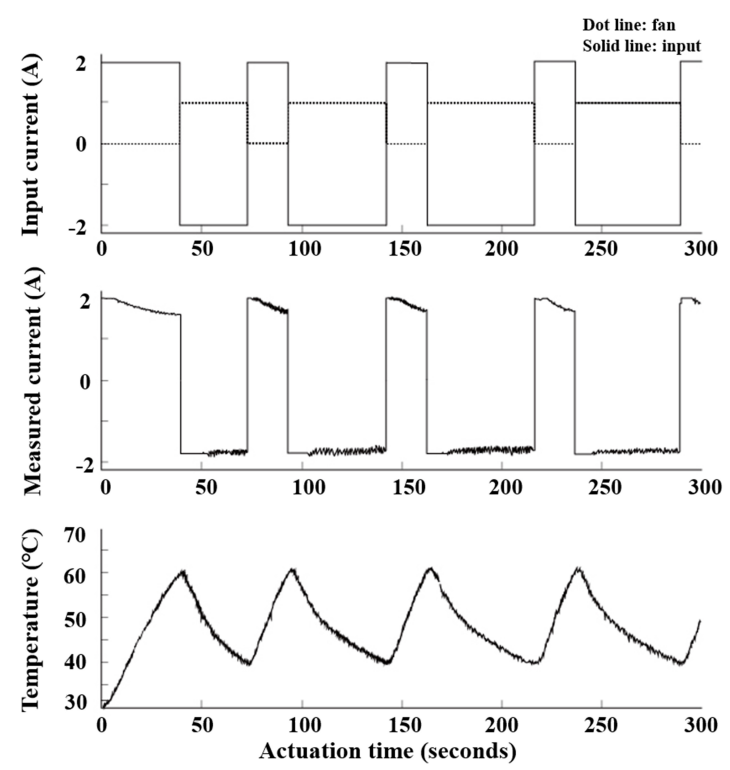

Fig. 8. Temperature variation during cooling-only fan ON state.
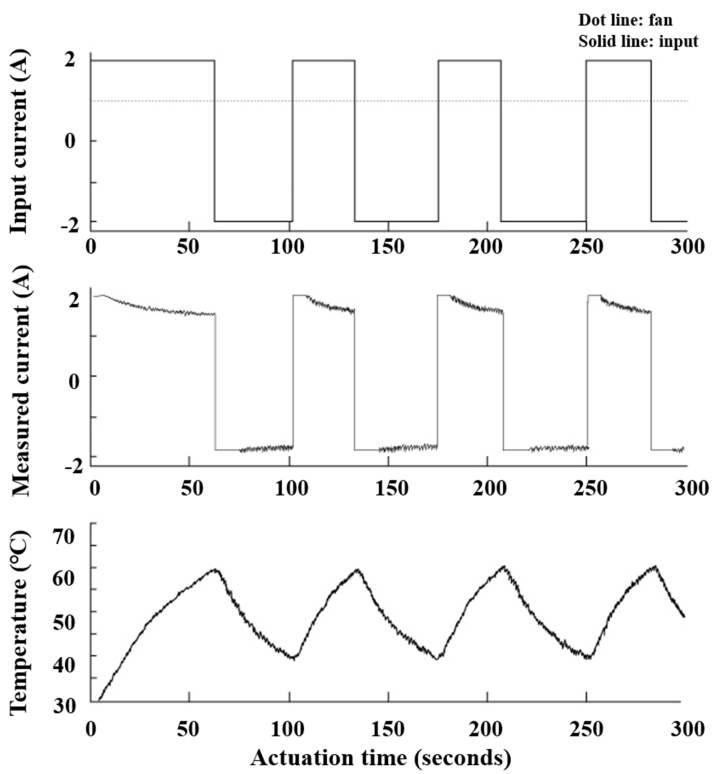

Fig. 9. Temperature variation during heating and cooling fan $\mathrm{ON}$ state.

\section{Experimental method}

The time required to cool down the MH module to the target temperature depends on the operating conditions of the MH actuator cooling fan. The MH module used in this study was fabricated to have a 3D structure that improved the heat transfer performance via thermal analysis. A radiating fan and a cooling fan were added to further improve the cooling efficiency. To compare the results on temperature 


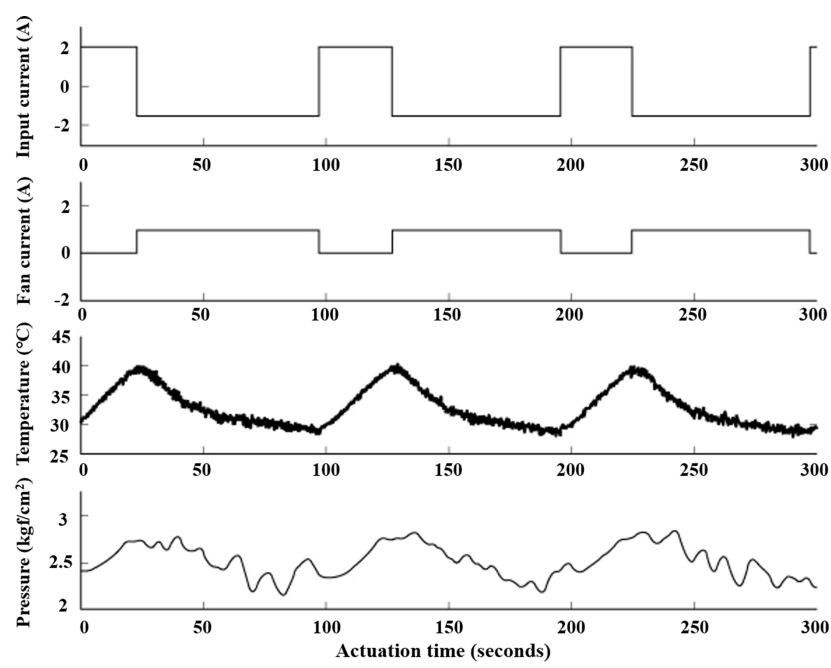

Fig. 10. $\mathrm{MH}$ actuator results $\left(30-40^{\circ} \mathrm{C}\right)$.

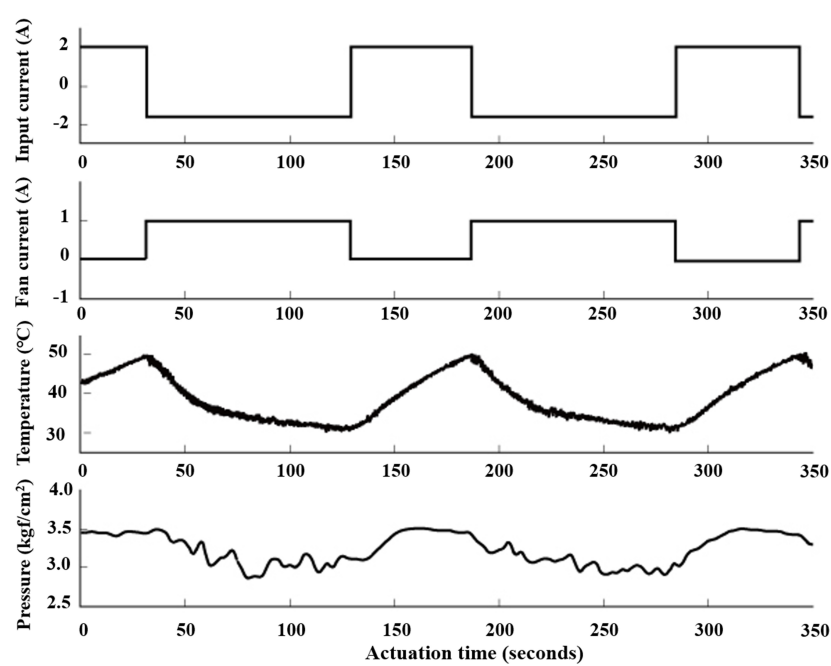

Fig. 11. $\mathrm{MH}$ actuator results $\left(30-50^{\circ} \mathrm{C}\right)$

control, which were based on the operating conditions of a cooling fan, the following two cases were compared: 1) both heating and cooling control the operation of a cooling fan, and 2) only cooling controls the operation of a cooling fan. The temperature was maintained between 40 and $60^{\circ} \mathrm{C}$.

The hydrogen gas contained in the hydrogen-absorbing alloy of the $\mathrm{MH}$ module drives a pneumatic actuator via an absorption-desorption process, which operates according to the heating and cooling performance of the Peltier element. More explicitly, the temperature-controlled Peltier element causes hydrogen gas to leave the $\mathrm{MH}$ module and enter the actuator, thereby driving an $\mathrm{MH}$ actuator. An experimental environment was constructed for the actuation of the MH actuators in Fig. 6. As shown in Fig. 7, software used to control the Peltier elements was also implemented for automatic and manual control of an $\mathrm{MH}$ actuator. In the automatic control mode, the $\mathrm{MH}$ actuator operated according to a specified temperature range. In the manual control mode, $\mathrm{MH}$ actuator operation was controlled by an operator. 
Each control mode was programmed to include optional items such as a heating/cooling mode, ON/OFF function for the cooling fan, and the time/temperature range/number of repetition. LabVIEW (National Instruments), a commercial program, was used to design and implement the Peltier element and $\mathrm{MH}$ actuator controls.

The performance of the MH actuator, which drives a rehabilitative system for upper and lower extremities, was evaluated by carrying out an experiment applying two different constraints on temperature. More specifically, the driving experiments for the MH actuator were performed by regulating the heating and cooling to ensure that the temperature was maintained within the following temperature ranges: 1) $30-40^{\circ} \mathrm{C}$, and 2) $30-50^{\circ} \mathrm{C}$.

\section{Experimental results}

The experiment to verify the efficiency of the cooling fan, which was proposed to improve the cooling performance of the MH actuator, compared the performance under the following conditions: 1) both heating and cooling fan operation, and 2) only cooling fan operation. In Fig. 8, the graphs illustrate the fan operation during the process of cooling, whereas Fig. 9 presents the results of fan operation during processes of heating and cooling. The results shown in Figs 8 and 9 indicate that there are temporal variations of input current, measured current, and temperature. When the heating and cooling of a Peltier element was controlled via the $\pm 2 \mathrm{~A}$ input current, the actual measured current was initially found to be $\pm 2 \mathrm{~A}$; this value was observed to marginally decrease subsequently. This decrease may have occurred because, as the Peltier element was heated, the ohmic resistance of the element increased; as a result, the current flowing through the Peltier element decreased. In addition, when the fan was ON only during cooling, the cycle of temperature variation was approximately 1.15 times shorter than that of the other case in which the fan was ON during both heating and cooling.

The hydrogen-absorbing alloy exhibited stable operation at or below $10 \mathrm{~atm}$ when the actuator temperature was maintained between 30 and $60^{\circ} \mathrm{C}$. Figures 9 and 10 illustrate the results of repeated operation of the $\mathrm{MH}$ actuator at temperatures ranging between 30 and $40^{\circ} \mathrm{C}$ and 30 and $50^{\circ} \mathrm{C}$, respectively. The horizontal axis of each graph indicates time, whereas the vertical axes correspond to input current, fan operation current, driving pressure, and temperature change, respectively. To improve the cooling efficiency of $\mathrm{MH}$ actuator, fan operation current was applied only when the fan is cooling. The driving pressure of $\mathrm{MH}$ actuator, which was measured in the temperature range of $30-40^{\circ} \mathrm{C}$ was $2-3 \mathrm{~atm}$. On the other hand, when the temperature control range was expanded to $30-50^{\circ} \mathrm{C}$, a higher range of 2.5-3.5 atm was measured. This may be because, as the temperature range was expanded, the driving pressure increased a little according to the PCT curve of the selected hydrogen-absorbing alloy.

\section{Conclusion}

A MH module able to improve heat transfer performance was fabricated, and a $\mathrm{MH}$ actuator, which was driven according to a predetermined temperature range of a Peltier element, was developed.

The objectives of this research were to fabricate an MH module that had face contact with the Peltier elements, thereby improving heat transfer performance, and to develop a new type of $\mathrm{MH}$ actuator that effectively utilized the hydrogen mechanism to assist a motion of rehabilitation system. To achieve these objectives, fan operation was only permitted during cooling to select an appropriate hydrogen-absorbing alloy for a low-temperature and low-pressure rehabilitative system, and the variation in $\mathrm{MH}$ actuator 
driving pressure was determined according to the PCT curve of the selected alloy that resulted from restricting temperature to within two different ranges. As a result, the range of temperature control of Peltier elements can be customized to achieve the appropriate assistive torques of elbow and knee joints, which are the primary joints of upper and lower extremities. In a future study, the performance of an upper/lower extremity rehabilitative system will be validated by directly implementing a pneumatic actuator in the system.

\section{Acknowledgments}

This material is based upon work supported by the Ministry of Trade, Industry and Energy (MOTIE, Korea) under Industrial Technology Innovation Program (10068076) and supported by Basic Science Research Program through the National Research Foundation of Korea (NRF) funded by the Ministry of Education (2015R1D1A1A01059525, 2015R1D1A1A01057463).

\section{Conflict of interest}

None to report.

\section{References}

[1] Shimizu S, Ino S, Sato M, Odagawa T, Izumi T, Takahashi M, Ifukube T. A basic study of a force display using a metal hydride actuator. 2nd IEEE International Workshop on Robot and Human Communication 1993 Nov. 3-5; Tokyo, Japan.

[2] Shimizu S, Ino S, Sato M, Izumi T, Ifukube T, Muro M, Takeda H, Wakisaka Y. A new method of variable compliance for a force display system using a metal hydride actuator. 3rd IEEE International Workshop on Robot and Human Communication 1994 July 18-20; Nagoya, Japan.

[3] Wakisaka Y, Muro M, Kabutomori T, Takeda H, Shimizu S, Ino S, Ifukube T. Application of hydrogen absorbing alloys to medical and rehabilitation equipment. IEEE Trans Rehab Eng 1997; 5(2): 148-157.

[4] Tsuruga T, Ino S, Ifukube T, Sato M, Tanaka T, Izumi T, Muro M. A basic study for a robotic transfer aid system based on human motion analysis. Advanced Robotics 2000; 14(7): 579-595.

[5] Ino S, Hosono M, Sato M, Nakajima S, Yamashita K, Izumi T. A soft metal hydride actuator using LaNi5 alloy and a laminate film bellows. IEEE International Conference on Industrial Techonology (ICIT) 2009; Feb 11-13; Victoria, Australia.

[6] Ino S, Sato M, Hosono M, Nakajima S, Yamashita K, Tanaka T, Izumi T. Prototype design of a wearable metal hydride actuator using a soft bellows for motor rehabilitation. 30th Annual International IEEE EMBS Conference 2008 Aug 20-25; Vancouver, BC, Canada.

[7] Ino S, Sato M, Hosono M, Izumi T. Development of a soft metal hydride actuator using a laminate bellows for rehabilitation systems. Sensors and Actuators B: Chemical 2009; 136: 86-91.

[8] Kurosaki K, Maruyama T, Takahashi K, Muta H, Uno M, Yamanaka S. Design and development of MH actuator system. Sensors and Actuators A 2004; 113: 118-123.

[9] Sato M, Ino S, Yoshida N, Izumi T, Ifukube T. Portable compressor system using MH alloys, employed as assistive devices. IEEE Region 10 Conference (TENCON 2006) 2006 Nov 14-17; Hong Kong, China.

[10] Ino S, Sato M, Hosono M, Nakajima S, Yamashita K, Izumi T. Preminary Design of a simple passive toe exercise apparatus with a flexible metal hydride actuator for pressure ulcer prevention. 32nd Annual International Conference of the IEEE EMBS 2010 Aug 31-Sep 04; Buenos Aires, Argentina.

[11] Hosono M, Ino S, Sato M, Yamashita K, Izumi T. A system utilizing metal hydride actuators to achieve passive motion of toe joints for prevention of pressure ulcers: A pilot study. Rehab Res Practice 2012; 1-7.

[12] Lloyd GM, Kim KJ. Smart hydrogen/metal hydride actuator. Intl J Hydrogen Energy 2007; 32: 247-255.

[13] Kwon TK, Pang DY, Choi KH, Kim YY, Lee SC, Kim NG. Development of a SMH actuator system using hydrogenabsorbing alloys. Smart Mater Struct 2006; 15: 1-7. 
[14] Kwon TK, Hong KJ, Kim K, Jeon WS, Pang DY, Lee SC, Kim NG. Development of SMH actuator system using hydrogen-absorbing alloy. J Control Autom Syst Eng 2007; 13(11): 1067-1073.

[15] Kim K, Kim SH. Analysis of heat transfer characteristic of metal-hydride module for the actuation of a rehabiliation system. Journal of Rehabilitation Welfare Engineering and Assistive Technology 2017; 11(2): 165-171.

[16] Kim K, Kim JJ, Kim JN, Chong WS, Yu CH, Kwon TK. Suggestion of novel actuator for assitive and rehabilitative device of the elderly and people with disability. 37th Annual International Conference of the IEEE EMBS 2015 Aug 25-29; Milan, Italy.

[17] Park JM. A study on the hydrogenation characteristics of Zr-based laves phase intermetallic compounds. Daejeon (ROK): KAIST; 1990. 